\title{
Energy policy and regional inequalities in the Brazilian economy
}

\author{
Gervasio F. Santos a,b,c, Eduardo A. Haddad ${ }^{\text {de, }, *, 1}$, Geoffrey J.D. Hewings ${ }^{\text {e }}$ \\ a Department of Economics, Federal University of Bahia, BA, Brazil \\ ${ }^{\mathrm{b}}$ Regional and Urban Economics Lab (NEREUS), SP, Brazil \\ c Visiting Scholar at Regional Economics Applications Laboratory (REAL), University of Illinois, Urbana, USA \\ d FEA, University of São Paulo and Regional and Urban Economics Laboratory (NEREUS), SP, Brazil \\ e Regional Economics Applications Laboratory (REAL), University of Illinois, Urbana, USA
}

\section{A R T I C L E I N F O}

\section{Article history:}

Received 5 September 2011

Received in revised form 3 August 2012

Accepted 22 August 2012

Available online 30 August 2012

\section{JEL classification:}

P25

P28

C68

R13

Keywords:

Energy policy

Regulation

Spatial concentration

CGE modeling

\begin{abstract}
A B S T R A C T
The objective of this paper is to evaluate the long-run regional impacts of the tariff policy of the Brazilian electric power sector. This sector has undergone a reform process that started in the 1990s. Since the beginning of the reform, two spatial trends of distribution of electric power tariffs have emerged among the Brazilian states, one of convergence and another of spatial divergence. These trends have been guided by the new electric power tariff policy and by the spatial features of the Brazilian economy, which is marked by a high degree of spatial concentration and hierarchical distribution of large markets. In addition, because of the presence of strong economies of scale, the recent electric power prices differentials might be caused by differentials in market size that provide better conditions for the achievement of economies of scale for electric power utility companies located in larger markets. Given the role of electric power as an important intermediate input in the production process and the interdependence between sectors, an Energy Interregional Computable General Equilibrium model was used to simulate the long-run regional impacts of electric power tariff policy in Brazil. The simulations showed that the heterogeneity of energy-intensity and the differentials of energy substitution drive the spatial impacts of changes in electric power prices. On the other hand, the recent trend of spatial dispersion of electric power prices might contribute to a decrease in the long-run economic growth and to an increase in the regional inequalities in Brazil.
\end{abstract}

(c) 2012 Elsevier B.V. All rights reserved.

\section{Introduction}

Since the 1990s, the energy sector in Brazil has been the subject of a variety of reform initiatives that are changing the market structure and the energy price levels. These reforms were triggered by the implementation of Plano Real and new liberal policies in the Brazilian economy. In this context, energy policy has stimulated energy diversification to increase the inter-fuel substitution. This policy might have changed the sectoral and regional consumption pattern of energy in the country towards sectors and regions that are more or less energy-intensive. In the electric power sector, these reforms led to a new industrial organization and a new tariff policy implemented through a price-cap regime by the Brazilian Electric Power Regulatory Agency (ANEEL). During the implementation of the reforms and the tariff policy, the spatial evolution of tariffs presented a trend of spatial convergence. However, after the consolidation of the tariff policy, the spatial evolution of tariffs has shown that the richest regions are experiencing lower tariffs than the poorest regions. This outcome

\footnotetext{
* Corresponding author at: FEA, University of São Paulo and Regional and Urban Economics Laboratory (NEREUS), SP, Brazil.

E-mail address: ehaddad@usp.br (G.F. Santos).

${ }^{1}$ CNPq scholar.
}

has raised some issues about the impacts this tariff policy may have had on regional inequalities.

The Brazilian economy is marked by a high degree of heterogeneity in industrial composition on the one hand and spatial concentration on the other (Azzoni, 2001; Haddad, 1999). After several decades of government policies designed to decrease this concentration, the effectiveness of these policies has been modest. Table 1 shows that in $2004^{2}$ the Southeast region, the richest, concentrated $55.4 \%$ of the Brazilian GDP, while the North, the poorest, only $5.0 \%$. On the other hand, the poorest regions had the highest electric-power-intensity. The analysis of the impacts of changes in the electric power prices faced by differentials of demand, income level and energy substitution provide important elements to the evaluation of the impacts of energy policies in Brazil.

According to the literature, energy-intensive sectors are the main channel through which energy price shocks affect the economy. These sectors and energy sectors themselves were in the core of the development policies of the country in the 1970s. As a consequence, the growth of these sectors strengthened the sectoral and spatial links in the Brazilian economy. In addition, the spatial concentration

\footnotetext{
${ }^{2}$ The year of the interregional input-output table developed to calibrate the CGE model used in the simulations.
} 
Table 1

Economic concentration and electric-power-intensity in Brazil, 2004.

Source: Brazilian Institute of Geography and Statistics and Brazilian Electric Power Agency.

\begin{tabular}{lrcl}
\hline Regions & \multicolumn{1}{c}{ GDP } & Electric power consumption & Electric-power-intensity* \\
\hline North & $5.0 \%$ & $6.6 \%$ & 0.168 \\
Northeast & $12.9 \%$ & $16.9 \%$ & 0.165 \\
Center-West & $9.1 \%$ & $5.4 \%$ & 0.075 \\
South-East & $55.4 \%$ & $53.5 \%$ & 0.111 \\
South & $17.6 \%$ & $17.6 \%$ & 0.127 \\
Brazil & $100.0 \%$ & $100.0 \%$ & 0.126 \\
\hline
\end{tabular}

${ }^{*}\left(\mathrm{GWh} / 10^{6} \mathrm{GDP}\right.$ in $\mathrm{R} \$$ of 2004$) .{ }^{11}$

${ }^{11} \mathrm{GWh}$ is abbreviation of Gigawatts/hour.

of energy-intensive sectors followed the same pattern of the spatial concentration of the whole economy. In $2004,82.6 \%$ of the valueadded of the energy-intensive sectors was concentrated in the CenterSouth region of Brazil. However, electric power consumption of these sectors amounted to $70.6 \%$ in the same region. This $10 \%$ difference can be attributed to a set of regional factors such as energy diversification, product differentiation that increases value-added, economies of scale and more efficient energy uses. As result, there is pronounced spatial heterogeneity of the electric-power-intensity in the energy-intensive sectors and in the economy as a whole (Santos et al., 2009). For this reason, energy price changes may result in differential regional impacts.

Considering the sectoral and spatial input-output linkages and factor mobility, the main focus of this paper is to explore the regional impacts of the tariff policy of the electric power sector on the Brazilian economy. To answer these questions three important elements must be considered. First, electric power price differentials in Brazil might be emerging from the relative differences among market sizes. Secondly, the regional impacts of price differentials might have been strengthened by economies of scale in the larger markets. Thirdly, the heterogeneity of energy supply in Brazil might determine an unequal pattern of energy substitution among regions. To incorporate all these elements in the analysis, an Inter-regional Computable General Equilibrium Model (ICGE), ENERGY-BR, will be calibrated and used to simulate the regional impacts.

In addition to this introduction, the paper has seven other sections. Section 2 presents the tariff policy and the spatial distribution pattern of electric power tariffs in Brazil. Section 3 describes the main findings of past studies about energy in the regional science field and some New Economic Geography elements (NEG) that combine vertical linkages and capital mobility to explain agglomeration economies. Section 4 describes the structure of the ICGE model that will be used to simulate the results while Section 5 reports the data set and key parameters used to calibrate the ENERGY-BR model. Section 6 accounts for the simulation strategy and basic experiments, with the results presented in the following section. Finally, Section 8 provides some summary commentary.

\section{Spatial distribution of electric power tariffs in Brazil}

The Brazilian electric power system is a large-scale hydrothermal system, where the high voltage networks interconnect transmission systems and generation plants to form the National Interconnected System (NIS). The NIS is a national grid composed of four interconnected subsystems. It optimizes the operation of public and private generation and transmission companies in the whole country and is responsible for $96.6 \%$ of the electric power supplied in Brazil. The remaining $4.0 \%$ is supplied through the small isolated systems located in the Amazonian region.
In 2007, the electric power sector system produced $444.5 \mathrm{TWh}^{3}$ of electric power. Hydroelectric with $84.1 \%$ and gas-fired thermoelectric generation with $3.5 \%$ were the two main sources of electric power. From this amount, $89.4 \%$ was produced by public services electric power companies and 10.6 by independent and self-producers. The distribution to final consumers is performed by 64 private electric power utilities companies operating under a public services concession regime together with 34 rural electrification companies.

The sector is still adjusting to a set of reforms that began in 1993. These reforms were introduced to stimulate private investments after a long period of finance imbalances in the sector. As a first step, in 1993, the rules for the private agents to supply public services were defined under the auspices of the well known Concession Law. ${ }^{4}$ Subsequently, in 1995, the privatization of the state-owned electric power utility companies began. A year later, the ANEEL was created; this is an independent regulatory agency responsible for enforcement rules, tariff policy and consumers' rights regarding the electric power sector. The same law that created the ANEEL also created a new industrial organization for the sector through the segmentation of the vertically integrated public monopolies to distinguish generation, transmission, distribution and trader companies (Landi, 2006). In order to address the economic balance of the profit motive of the companies on the one hand and the need to provide moderate tariffs to final consumers on the other hand, the ANEEL introduced an incentive regulation program through the adoption of a price-cap ${ }^{5}$ regime.

The price-cap regime simulates elements of a competitive market. An upper bound tariff to be charged by distribution companies is settled in the privatization contracts, based on the initial finance balance of the companies. This tariff is supposed to be adjusted yearly using a national price index minus a productivity index (X-Factor). In addition, a tariff review process is accomplished every 4 years to redefine the productivity index in a way to transfer productivity gains from distribution companies to final consumers. The higher the productivity, the higher is the X-Factor and lower is the yearly tariff adjustment. In the period before and after the tariff review process, electric power utility companies have incentives to become more productive, because they might internalize the productivity gains and increase their returns.

The main element of new tariff policy is the redefinition of the $X$-Factor by the regulatory agency during the tariff review process. The ANEEL carried out two review processes; the first in the 2003/ 2004 and the second in 2007/2008. Before 2003, the X-Factor was set to zero. To revise the $X$-Factor, usually the regulator grounds this variable in the studies concerning Total Factor Productivity (TFP) and efficiency of electric power companies. In a recent econometric study, Ramos-Real et al. (2009) showed that only after 2004 did electric power distributors start to present satisfactory productivity indexes and positive rates of return. The same study also shows that companies with a smaller rate of electric power supply by kilometer $(\mathrm{kWh} / \mathrm{km})$ of distribution networks tend to present weak performance compared to those with a larger rate. In addition, Tovar et al. (2009) also showed that the size of the companies is an important element to determine the evolution of productivity. In summary, there might be evidence that market and company sizes determine the tariff gap among the Brazilian regions, triggered by the transference of productivity gains to final consumers.

Fig. 1 shows evolution of electric power real average tariff in Brazil. From 1995 to 2008, the tariff increased by $360.6 \%$. It was at R\$ $57.12 / \mathrm{kWh}$ in 1995 and increased to $\mathrm{R} \$ 263.22 / \mathrm{kWh}$ in 2008 . In the same period, the inflation rate increased $184.6 \%$. The tariff increases above the inflation rate affects the rate of return for the electric power sector and thus should stimulate new private investments in

\footnotetext{
3 Tigawatts/hour.

${ }^{4}$ Law no. 8.987/1995

${ }^{5}$ See Littlechild (1983).
} 


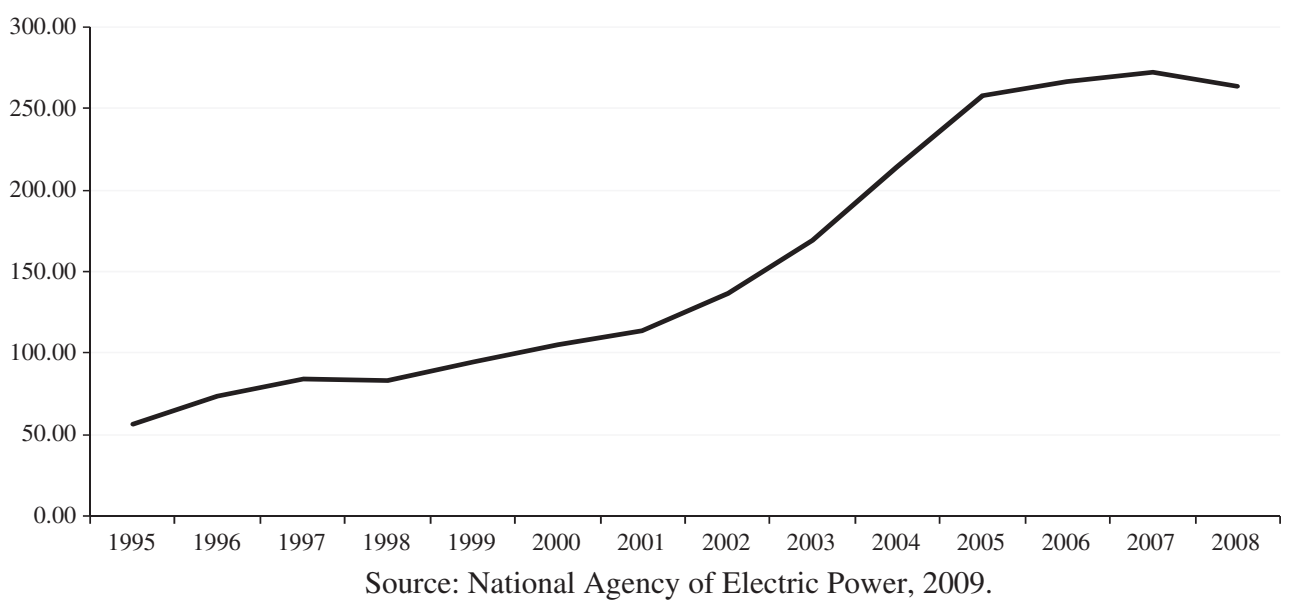

Fig. 1. Evolution of electric power real average tariff (R $\$ / \mathrm{kWh})$ in Brazil, 1995-2008.

the sector. However, after 2004, the tariff increases slowed and in 2008 started a mild decrease. This final trend might be reflecting the financial recovery of the sector. The spatial aspects underlying the tariff gap among the Brazilian states in this period provide important insights into the analysis.

In addition, Fig. 2 shows the spatial distribution of the percentage variation of electric power average tariff by states for three selected periods. The period 1995-2002 comprises the beginning of privatization process and the implementation of the new tariff. During this period, the highest percentage increases were found in the Southeast and Center-West states. These two regions and the South region presented the lowest tariffs in the 1995. Regarding the period 2003-2005, which coincides with the first tariff review process, though the highest increases were found in the states of Mato Grosso do Sul and Minas Gerais belonging to the Center-West and Southeast region respectively, the spatial pattern of the highest percentage increases occurred in the Northeast region. Finally, in the period 2006-2008, the second tariff review process period, except for the state of Mato Grosso do Sul, the highest increases were again in the North and Northeast states. In several of the more prosperous states of the South, Southeast and Center-West regions, the average tariff decreased in this last period.

From 1995 to 2004, the electric power tariff's evolution occurred during a period of the enforcement of the regulatory rules regarding tariff realignment, the end of special contracts of electric power supply and the price-cap regime. The year of 2004 might be characterized by the consolidation of regulatory rules, the beginning of positive rates of return and favorable productivity gains for the electric power utility companies. On the other hand, this period was also characterized by the end of tariff convergence among Brazilian states.

Fig. 3 shows the evolution of the squared deviation of the relation between the tariffs by state and the national average tariff. As can be seen, the deviation declined from 1995 to 2004, and after 2004 started to increase again; hence, 2003-2004 marks a period with the smallest tariff gap among the Brazilian states. After this period, the tariff review process determined a new trend in the spatial distribution of these tariffs.

In order to detect some spatial pattern in the tariff distribution, the spatial autocorrelation coefficient through the Moran Index ${ }^{6}$ was calculated. The evolution of this coefficient, in Fig. 4, showed that from 1995 to 2008 there was a spatial pattern of tariff distribution where states with highest tariffs were close to other states also with the highest tariffs. On the other hand, states with the lowest tariffs were also close to other states with the lowest tariffs. However, this

\footnotetext{
${ }^{6}$ Anselin, (1988).
}

pattern is not homogeneous within the period. From 1995 to 2003, the spatial autocorrelation decreased. After 2003, when the tariff review process started, and the benefits of productivity gains started to be transferred to consumers, the spatial autocorrelation started to increase. In summary, the data point to a different spatial pattern of tariff distribution, before and after the beginning of the tariff review processes. This pattern is characterized by lowest tariffs appearing in the South and Southeast regions in the end of the period.

The increasing spatial dispersion of electric power tariffs in Brazil might be the result of the methodology applied by ANEEL in the tariff review processes. In the first tariff review process, the $X$-Factor was replaced in a way that the distribution companies located in less developed regions and with smaller demand density had higher tariff increases. On the other hand, in the second tariff review process, the tariffs of the companies located in the more developed regions were reduced through the transference of productivity gains to final consumers (Sales, 2009). This fact contributes to the enlargement of the spatial heterogeneity of tariffs after 2004.

Although this analysis considers the market for captive consumers, and the possibility of convergence and spatial dispersion of tariff might differ across consumers segments, it is possible to conclude that there is a strong relationship between the spatial distribution of tariffs and the spatial concentration of economic activity in Brazil. In the large markets, electric power tariffs are becoming considerably lower than those in the small markets. One must also consider that Brazilian poorer regions had received more investments to extend electric power services to low income and rural households; these decisions increased distribution costs and may have contributed to increases in the electric power tariffs in the same regions. However, in the long run, the trend of lower tariffs in the more developed regions might contribute to the displacement of economic activity, enlarging regional inequalities in Brazil.

\section{Energy and regional science}

The relation between energy policy and regional issues is relatively well known in the regional science field. There is a considerable literature providing a range of issues concerning the scope of energy policy in the context of a spatial economy (see Lakshmanan, 1981; Lakshmanan and Bolton, 1986; Nijkamp, 1980, 1983; Nijkamp and Parrels, 1988). These studies were primarily focused on the relationship between energy supply and demand and the spatial distribution of activities. The main results were that the spatial distribution of households, firms and infrastructure systems has strong implications for energy systems, particularly for the size of energy plants. Furthermore, the heterogeneous distribution of energy resources may affect land uses, transport systems, and environmental policies. 

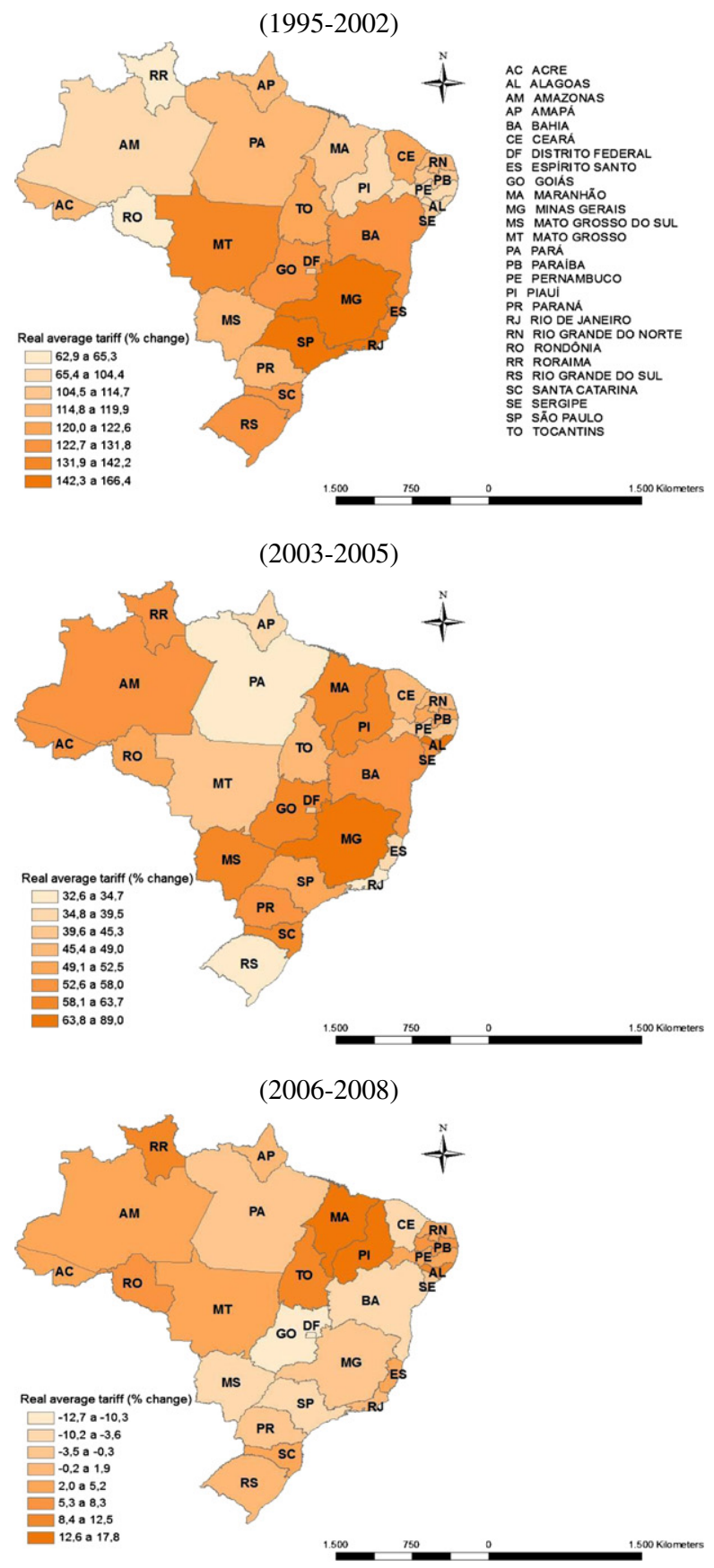

Source: National Agency of Electric Power (ANEEL), 2009

Fig. 2. Average tariff change, \%, by states in Brazil, 1995-2008.

Regarding the link between energy and location and the performance of economic activities, Miernyk $(1976,1977)$ and Nijkamp and Parrels (1988) focused on these relationships with a concentration on energy-intensive sectors. Although the results were not so clear, the high energy dependence makes these sectors the main channel through which disturbances such as prices, taxes, subsidies, environment regulations in energy markets affect the equilibrium among regions. Better knowledge of the links between economic activity and energy sectors would enhance the understanding of the spatial impacts of energy policy.

These perspectives have been enhanced as a result of recent theoretical advances in the New Economic Geography (NEG) that has introduced more spatial elements into the core of economic theory. Using trade models (see, Krugman, 1980, 1991), the NEG formalizes the agglomeration forces derived from endogenous market size. The main assumption is that sectors characterized by increasing returns, imperfect competition and transport costs tend to locate in the regions that provide excellent market access conditions (Fujita et al., 1999).

Although the NGE models have still proven difficult for empirical tractability, they have launched a new challenge to regional science. Despite the difficulty in modeling the NEG elements in a general equilibrium framework, they provide important insights into the focus of this paper. For example, the gap in electric power tariffs might be caused by differentials of agglomeration economies. The richest and most industrialized regions provide the biggest gains for consumers and producers. In electric power utility distribution, the productivity gains are due to greater economies of scale in areas with higher demand density. The tariff policy ensures that these gains are transmitted to final consumers through decreasing prices. Thus, although the NEG will not be formally introduced into the modeling framework, in the next section of this paper, it makes sense to analyze the impact of the electric power price differentials, in the presence of some theoretical elements of the NEG.

\section{Energy Inter-regional Computable General Equilibrium Model}

To evaluate the long-run effects price increases of electric power in Brazil, an Interregional Computable General Equilibrium Model (ICGE) model, ENERGY-BR, was developed and implemented. The structure of this model represents a further development of the 27 region Brazilian Multi-sectoral and Regional/Interregional Model (B-MARIA-27), a widely used and well documented ICGE model for the Brazilian economy (Haddad, 2004; Haddad and Hewings, 2005). Moreover, the ENERGY-BR model incorporates energy substitution modeling from the MMRF-Green model (Adams et al., 2003). The sectoral disaggregation recognizes the energy and the energy-intensive sectors of the Brazilian Energetic Balance. Table 2 shows the ENERGY-BR model sectors.

The agent's behavior of ENERGY-BR model is modeled at the regional level to accommodate variations in the structure of the regional economies. Results are based on a bottom-up approach, whereby national results are obtained from the aggregation of regional results for each of the 27 Brazilian states. In each state, the model identifies 30 sectors producing 30 commodities, 30 investors that organize the capital creation, one representative household, one regional and one federal government, and a single foreign consumer who trades with each state. The model also recognizes three primary factors in each state: capital, labor and land.

The core of the model is shaped by supply, demand and market clearing equations. These equations determine the regional supply and demand based on assumptions of optimizing behavior of agents in competitive markets at the microeconomic level. The national labor supply is determined by demographic factors, while supply of capital responds to a rate of return. Capital and labor are mobile among regions. For this reason, regional factor endowments reflect the regional opportunities for jobs and relative rates of return. Considering zero profit, the producer price is equal to marginal cost in each sector of the regional competitive markets. Except from the labor market, where excess demand might be specified, the demand is equal to supply in every market. Intervention in the market might be carried by the government through taxes and subsidies, for instance, in a way to set up price differentials between the purchasing and selling price. Two commodities are specified as margins: transport and domestic trade.

The structure of the model is represented by five blocks of an integrated system of equations: CGE core; capital accumulation and investment; public finance, foreign debt accumulation; and labor market and regional migration. The energy substitution processes takes place within the CGE core that assembly the production process (demand by inputs), household demand, investment (capital 


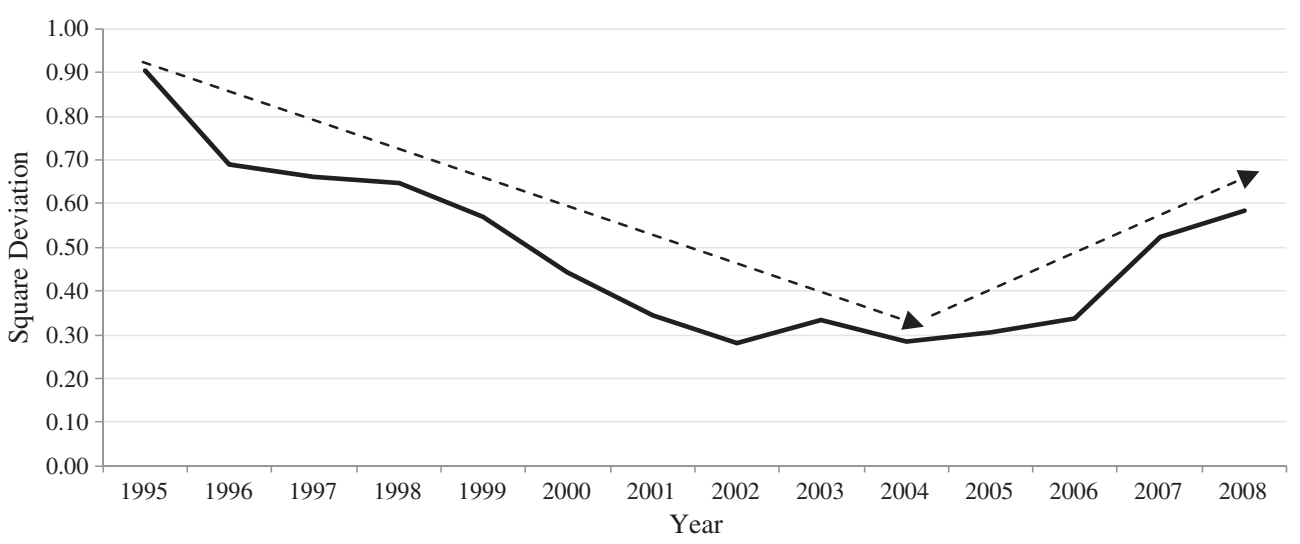

Source: National Agency of Electric Power (ANEEL), 2009

Fig. 3. Evolution of square deviation from the relation between average tariff by state and the national tariff in Brazil, 1995-2008.

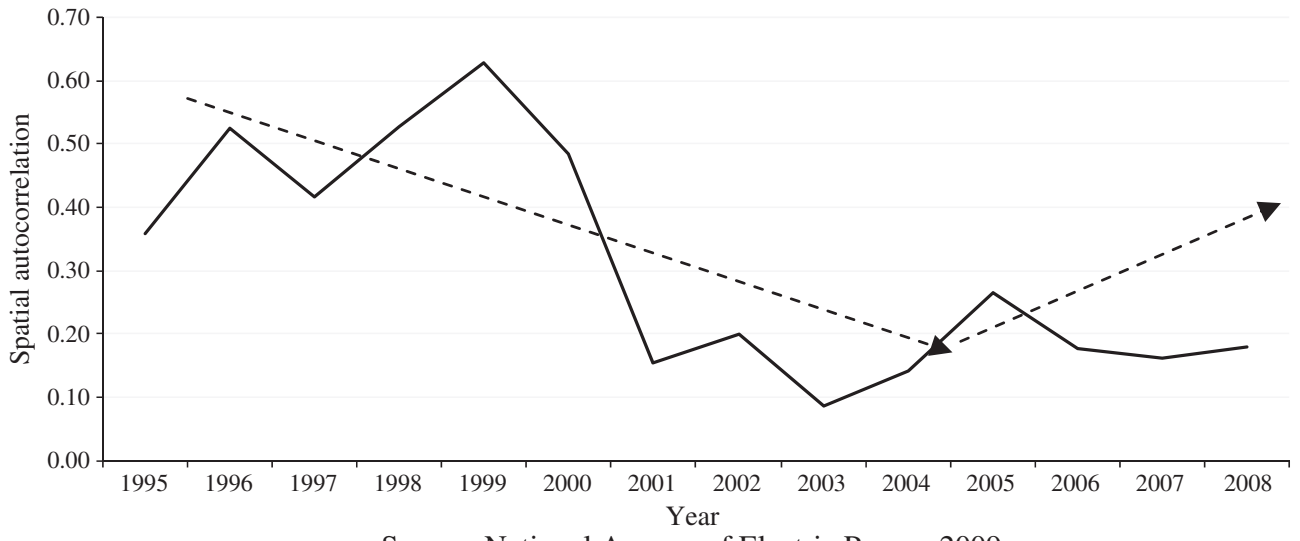

Source: National Agency of Electric Power, 2009

Fig. 4. Spatial autocorrelation among average tariffs by state in Brazil, 1995-2008.

creation), government demand and foreign demand. In this paper, only the production structure will be described. Full details of the model may be found in Santos (2010). The regional nested production technology of the ENERGY-BR model is presented in Fig. 5. Aside from primary factors, the model recognizes two classes of intermediate inputs: non-energy inputs and energy inputs. Each individual firm chooses an input mix that minimizes the production costs for a given production level. Two energy substitution processes take place into the production structure, one among energy inputs and another among electric power sources. Although the electric power supply is concentrated around the hydroelectric power, with $84.1 \%$ of the total supply, it is important to model the substitution among the electric power sources. The thermoelectric generation from some sources such as gas-fired and biomass, for example, has begun to appear in the Brazilian electric system. Since the ENERGY-BR is the first ICGE model designed for energy policy analysis in Brazil, it is important to capture the energy substitution advances from the CGE models for the analysis of energy policy in Brazil.

As can be seen in Fig. 5, in the first level, intermediate inputs, energy inputs and primary factors are demanded in fixed proportions per unit of output through a Leontief production technology. In the second level, for non-energy inputs, vectors of aggregate inputs are framed through a $\mathrm{CES}^{7}$ technology that allows for the substitution between domestic and imported inputs using the Armington assumption of imperfect substitution among inputs. In the third level, also

\footnotetext{
${ }^{7}$ Constant Elasticity of Substitution.
}

for non-energy inputs, vectors of domestic inputs are formed through CES, combining inputs from different domestic regions, also using the Armington assumption. The CES technology is also used to combine labor, capital and land to frame an aggregated primary factors vector.

For the energy inputs, in the first level, each firm demands an energy composite and an electric power composite (direct from generation plants), in fixed proportions per unit of output through the Leontief production technology. The energy composite refers to a combination of oil refining products, natural gas and electric power (sectors 7, 23 and 24 in Table 2). Regarding electric power, the substitution among the seven generation sources in Table 2 is allowed through a CES or CRESH technology ${ }^{8}$ (Dixon et al., 1982, 1992; Hanoch, 1971; Hinchy and Hanslow, 1996). The resulting electric power composite might be demanded by electric power utility distribution sector or directly by the other sectors. ${ }^{9}$

The interregional modeling is an important feature to evaluate the spatial results. Haddad and Hewings (2005) concluded in the previous analysis using the B-MARIA model, that interregional substitution is the key mechanism that drives the model's spatial results. Moreover, the interregional linkages play an important role in the functioning of ICGE models. These linkages are driven by trade relations (commodity flow), and factor mobility (capital and labor migration). At this point, the estimation of interregional input-output databases

\footnotetext{
${ }^{8}$ Constant Ratio Elasticity Substitution Homothetic.

9 The electric power substitution modeling through the CRESH technology considers the technological bundle approach of Hinchy and Hanslow (1996), which electric power supply is a combination of weighted average of different generation technologies.
} 
Table 2

Sectors of ENERGY-BR model.

Source: ENERGY-BR specification (Santos, 2010).

\begin{tabular}{ll}
\hline Order & Sectors \\
\hline S1 & Agriculture and livestock \\
S2 & Mining (oil and gas) \\
S3 & Mining (ore, coal and other minerals) \\
S4 & Food and beverage \\
S5 & Textile \\
S6 & Paper and pulp \\
S7 & Oil refining \\
S8 & Ethanol \\
S9 & Chemical, rubber and plastic \\
S10 & Cement \\
S11 & Ceramic and glass \\
S12 & Metallurgy of steel and iron \\
S13 & Metallurgy of aluminum and cooper \\
S14 & Metal products \\
S15 & Other industries \\
S16 & Electric power - hydro \\
S17 & Electric power - thermo fuel oil \\
S18 & Electric power - thermo coal \\
S19 & Electric power - thermo diesel \\
S20 & Electric power - thermo - natural gas \\
S21 & Electric power - thermo - sugar cane biomass \\
S22 & Electric power - thermo other sources \\
S23 & Utility - electric power distribution \\
S24 & Utility - gas distribution \\
S25 & Utility - water distribution and sanitation \\
S26 & Construction \\
S27 & Domestic trade \\
S28 & Transport services \\
S29 & Services \\
S30 & Public \\
\hline &
\end{tabular}

is an important step to calibrate the model, and regional trade elasticities play a crucial role in the adjustment process.

The model is calibrated for the base year of 2004. This was the year of the last complete interregional input-output table for Brazil (Guilhoto, 2008). Like most CGE models, the number of unknowns of ENERGY-BR exceeded the number of equations. The model contains 7,397,126 equations and 7,466,034 variables, which involves determining 68,908 exogenous variables. However, the implementation of the model through the software GEMPACK made it possible to obtain a reduced version of the model with 63,229 equations and 92,492 variables, resulting in the determination of 29,263 exogenous variables. The nominal exchange rate was set as the numéraire. The choice of these exogenous variables allows the determination of the macroeconomic environment to run the policy simulations. ${ }^{10}$

Simulations using ENERGY-BR were carried out under two standard closures, referring to the short run and the long run. There is no dynamics in the model. The simulations with the ENERGY-BR model capture the effects associated with the static impact-effect question, i.e., given the structure of the economy, what-if questions can be addressed in a comparative-static framework. Short-run and long-run considerations differ in the way the equilibrating mechanisms are set through the closures specified. Structural changes are captured only through the evaluation of a re-allocation of resources. A main distinction between the short run and long run closures relates to the treatment of capital stocks encountered in the standard microeconomic approach to policy adjustments. The short-run closure was used to accomplish initial tests in the model, while the long-run closure was adopted for the simulations of the present study.

In the short-run closure, capital stocks are held fixed, while, in the long run, policy changes are allowed to affect capital stocks. In addition to the assumption of interindustry and interregional immobility

\footnotetext{
10 (Dixon and Rimmer, 2002).
}

of capital, the short-run closure includes fixed regional population and labor supply, fixed regional wage differentials, and fixed national real wage. Regional employment is driven by the assumptions on wage rates, which indirectly determine regional unemployment rates. Labor is, thus, mobile only across sectors within the same region. On the demand side, investment expenditures are fixed exogenously - firms cannot reevaluate their investment decisions in the short-run. Household consumption follows household disposable income, and real government consumption, at both regional and central levels, is fixed. Balance of payments has to adjust to changes in government deficit. Finally, preferences and technology variables are exogenous.

In the long-run, the assumptions on interregional mobility of capital and labor are relaxed and a steady-state-type of solution is achieved, in which regional natural unemployment rates and regional aggregate rates of return are reestablished. Moreover, balance of payment equilibrium is reflected in the hypothesis of fixed share of trade balance in GDP. From a spatial perspective, in the long run the 're-location' effect becomes relevant; as factors are free to move between regions, new investment decisions define marginal re-location of activities, in the sense that the spatial distribution of capital stocks and the population changes.

The main differences from the short run are encountered in the labor market and the capital formation settings. In the first case, aggregate employment is determined by population change, labor force participation rates, and the natural rate of unemployment. The distribution of the labor force across regions and sectors is fully determined endogenously. Labor is attracted to more competitive industries in more favored geographical areas, keeping regional wage differentials constant. While in the same way, capital is oriented towards more attractive industries, equalizing rates of return across space. In the long-run, the government deficit is set exogenously, allowing government expenditures to change.

Two caveats deserve attention at this point. First, ENERGY-BR provides results emanating from a given shock, from where one usually compares the changes in the variables of interest, but do not provide any insight on the dynamics to achieve these post-shock levels. One always wonders if transition was monotonic or if it has overshoot before setting in the final level. Perhaps a gradual relaxation of labor and capital mobility could shed some light on this with the introduction of recursive-dynamics mechanisms. Second, there are no natural resources constraints in the model, despite the assumption of fixed land. However, for the problem at hand, since over $84 \%$ of electricity is generated by hydro, a renewable resource, the long-run constraints are not seen as a main problem.

\section{Database and key parameters}

An interregional input-output table representing the inter-industry and inter-regional trade flows of 30 sectors (producing 30 commodities) and 27 Brazilian states was the main set of data used to calibrate the ENERGY-BR model. Before the construction of this set of data, it was necessary to adjust information about energy sectors in the Brazilian National Accounts System in the Use Table for the year 2004. The energy sectors enclosed in the aggregate sector "Industry Services of Public Utility" of the Use Table were disaggregated to form the subsectors of electric power generation, electric power utility transmission and distribution, natural gas utility distribution and water and sanitation utility. The data used to carry this process was the share of each subsector in the aggregate sector, provided by the Brazilian Institute of Geography and Statistics. In addition, the electric power generation was disaggregated to form seven sources of generation (see Table 2). To disaggregate these sources, use was made of the shares of the electric power generation supply of each source from the Brazilian Energy Balance. The disaggregation of these sources from the national level to the state level was 


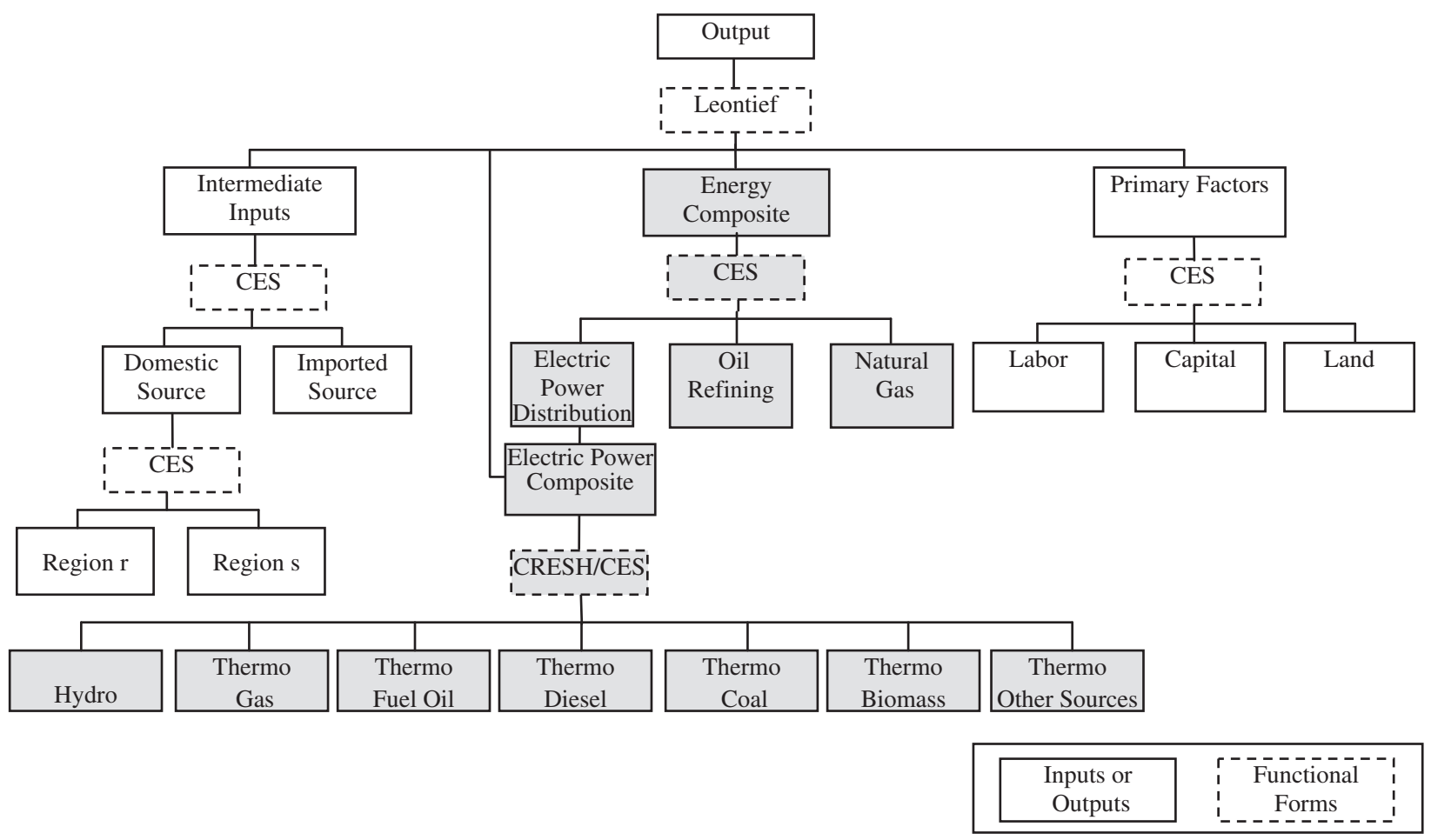

Fig. 5. Regional nested production technology.

carried using data of the share of each source in each Brazilian state though from the Brazilian Ministry of Mining and Energy.

The flows regarding the electric power produced by the selfproducers were also separated from that produced by the public service generators. In 2004, the electric power produced in Brazil amounted to $387.4 \mathrm{GWh}$; of this amount, the self-producers were responsible for $9.8 \%$. For this reason, it was assumed that all electric power from self-producers was sent directly to economic sectors in the input-output table and the $90.2 \%$ remaining was sent to the transmission and distribution sector. This strategy minimized further problems that could be caused by the possibility of larger consumers buying electric power directly from the generation plants or from self-producers in Brazil (this share represented 5.0\% of the market in 2004). Finally, the transmission and distribution sectors were aggregated into one sector due to the lack of information to disaggregate them. Transmission costs represented only $8.0 \%$ of electric power costs to final consumers in 2004 and were proportional to the electric power quantity distributed to final consumers. Therefore, it was assumed that the aggregation would not entail further problems in the implementation of the shocks in the CGE model.

All the above information was first used to generate an interregional input-output matrix recognizing 132 sectors of 27 Brazilian states for the year of 2004, based on the industry-by-industry technology (Guilhoto, 2008). Thereafter, this matrix was aggregated to obtain the interregional matrix with 30 sectors and 27 Brazilian states; this matrix used to calibrate the model.

Beyond the structural parameters from the input-output matrix, some sets of behavioral parameters were also used to calibrate the model. The Armington elasticities regarding regional substitution of inputs form one of these sets. These elasticities were obtained from the estimated elasticities to calibrate B-MARIA-27-COM (Haddad et al., 2008) and weighted by the 30 sectors aggregation of the ENERGY-BR model using the production matrix. Table 3 presents these parameters, which were also used to represent the Armington elasticities regarding the substitution between domestic and imported inputs.
Aside from the traditional difficulty to acquire (or to estimate) parameters to calibrate ICGE models, in the ENERGY-BR model three additional difficulties emerged. First, this was the first ICGE model designed for energy policy in Brazil and for this reason, there are no previous elasticities regarding the interregional substitution of electric power. Furthermore, it must be pointed out that the electric power utility companies have limited opportunity to displace its interregional demands of electric power. Those companies send their demands equivalent to 4 years of future consumption to the ANEEL and, afterwards, the ANEEL coordinates an auction in which energy blocks are supplied in locations that do not hold correspondence with the location of demand, mainly because of optimization of the supply accomplished through the NIS. In view of this process, the Armington elasticities for electric power generation sectors were set at 0.01 . Although more specific studies about the possibilities of substitution are necessary, this small value only symbolizes that interregional substitution of electricity by sectors is very close to zero. For this reason, it is not necessary to test another value. However, systematic sensitivity analyses were carried on these parameters and are presented in Section 7.4.

The second difficulty was regarding the parameters of substitution among the energy sources (electric power, natural gas and oil refining products). There are no parameters for Brazil in the literature. Although there are estimations in the international literature, it was decided to choose conservative values because of the specific features of the Brazilian economy. On the other hand, considering that one of the main elements in this substitution process is the natural gas supply and that this supply is still heterogeneous within Brazil, a differential feature was proposed for this source of energy. For the seven states (Mato Grosso do Sul, São Paulo, Paraná, Santa Catarina, Rio Grande do Sul, Rio de Janeiro and Minas Gerais) served by the natural gas supply through the Bolivia-Brazil pipeline, a conservative value of 0.20 for energy substitution was adopted for all sectors. For other states, the value used was 0.10 . These values were evaluated during the completion of systematic sensitivity analysis of the results during the simulations. 
Table 3

Armington elasticities used to calibrate the ENERGY-BR Model.

Source: based on econometric estimations of the B-MARIA-27-COM.

\begin{tabular}{lll}
\hline Order & Sectors & Parameters \\
\hline S1 & Agriculture and livestock & 2.403 \\
S2 & Mining (oil and gas) & 2.925 \\
S3 & Mining (ore, coal and other minerals) & 1.796 \\
S4 & Food and beverage & 2.464 \\
S5 & Textile & 3.561 \\
S6 & Paper and pulp & 2.052 \\
S7 & Oil refining & 1.163 \\
S8 & Ethanol & 3.530 \\
S9 & Chemical, rubber and plastic & 2.802 \\
S10 & Cement & 3.171 \\
S11 & Ceramic and glass & 3.099 \\
S12 & Metallurgy of steel and iron & 2.907 \\
S13 & Metallurgy of aluminum and cooper & 2.900 \\
S14 & Metal products & 2.183 \\
S15 & Other industries & 2.321 \\
S16 & Electric power - hydro & 0.010 \\
S17 & Electric power - thermo fuel oil & 0.010 \\
S18 & Electric power - thermo coal & 0.010 \\
S19 & Electric power - thermo diesel & 0.010 \\
S20 & Electric power - thermo - natural gas & 0.010 \\
S21 & Electric power - thermo - sugar cane biomass & 0.010 \\
S22 & Electric power - thermo other sources & 0.010 \\
S23 & Utility - electric power distribution & 0.010 \\
S24 & Utility - gas distribution & 0.010 \\
S25 & Utility - water distribution and sanitation & 0.001 \\
S26 & Construction & 0.002 \\
S27 & Domestic trade & 0.690 \\
S28 & Transport services & 1.400 \\
S29 & Services & 0.150 \\
S30 & Public & 0.070 \\
\hline & &
\end{tabular}

The final difficulty was related to the absence of substitution parameters among electric power sources. Aside from econometric estimation, these parameters could be derived through the use of bottom-up energy models. Econometric estimation for Brazil could make use of electric power prices from energy auction of ANEEL. However, these auctions are organized according to the energy availability and they do not depend on the generation source. For this reason, besides the use of CES technology that requires less parameters than the CRESH technology, for the energy-intensive sectors and for the transmission and distribution, the value of 0.15 was used for the substitution parameter and 0.10 for the other sectors. The values were also evaluated during the completion of systematic sensitivity analysis of the results. ${ }^{11}$

\section{Basic experiments, causalities and simulation strategy}

In this section, the elements concerning the implementation of the simulations, the causal relations and the simulation strategy in the ENERGY-BR model will be discussed.

\subsection{Implementation of the basic experiments}

The experiments encompass exogenous shocks in the basic prices of electric power supplied from distribution companies to captive final consumers to evaluate the long-run regional impacts of the tariff policy on the Brazilian electric power sector. The prices of the electric power purchased directly from the generation sector or self-production will be adjusted endogenously according to the market equilibrium. Basic prices are uniform among all the consumers and producers for both

\footnotetext{
11 The model was implemented using the software Version 10.0 (Horridge et al., 2008).
}

domestic and imported goods. Eq. (1) presents the simplified basic prices system of the ENERGY-BR model.

$p_{j r}^{0}=\gamma_{j r}+i c_{j r}$

In CGE modeling, commodity basic prices $\left(p^{0}\right)$ are usually equal to a unit cost index (IC), (intermediate and factor costs). Thus, an exogenous price-shift term $\left(\gamma_{j r}\right)$ was introduced in the equation and the shocks were implemented in the sector $j=23$ in all regions, $r=1$, ...,27. The shocks will directly affect all the consumption segments that buy electric power from the electric power utility sector. As a consequence, the electric power acquired from generation sectors by the large electric power consumers will not be directly affected by the exogenous shock, but it will be affected indirectly due to general equilibrium adjustments.

\subsection{Causal relations}

Fig. 6 shows the causal relations featured in the system of equations of the ENERGY-BR model. On the demand side, the equation blocks reveal that the shocks in the electric power basic prices, an increase for example, are directly transmitted to the purchase prices paid by agents in the economy, causing an increase in the price of composite goods. As a result, the price indexes of the economy will increase and the regional real income of firms, investors and families will decrease. The firms become less competitive, the investors obtain lower potential returns and families will become "poorer." The internal demand decreases leading to an increase in the exports. The production level of the economy will decrease, leading to a declining of primary factor demand. This result pressures the prices of primary factors to decrease, leading to the decrease in the price of goods.

On the supply side, an increase in the electric power price will generate decreases in the requirements of electric power services, and consequently, in the production of these sectors. Capital and labor of these sectors will be released, causing a surplus of primary factors supply that pressures the prices of these factors to decline, resulting in a decrease in the price of goods. On the other hand, because of energy substitution, the opposite effect will hold for the sectors that compete with electric power in the model. For this reason, the demand for oil refining and natural gas products might increase, resulting in an increase in the price of these respective products, as shown in Fig. 6.

The net effect will depend on the relative intensity of increases and decreases in the prices. The simulation considers the long-run closure, in which capital and labor are mobile. For this reason, aside from the regional trade elasticities, the spatial results will depend on the relative adjustments in the rate of return among the states.

One of the advantages of the ICGE applications is the possibility of capturing differential spatial effects. In the long-run, the relevant mechanism of adjustment is the "relocation" effect (Haddad, 2004). In the closure of the model, capital and labor are now considered to be mobile among regions. As a consequence, new investment decisions might define the marginal relocation of economic activities, through a new spatial distribution of capital stock and population dynamics. The main element responsible for these effects is the variation in the regional rate of return, given the fixed national rate of return. Therefore, considering the equations of the model, an increase in the investment price index will lead to a respective increase in the basic price for capital creation and a relative decline in the interregional rate of return. In the long-run, there might be inter-industry and inter-regional migration of factors. The hypothesis underlining the present study is that capital could migrate to sectors and regions with lower electric-power-intensity. 


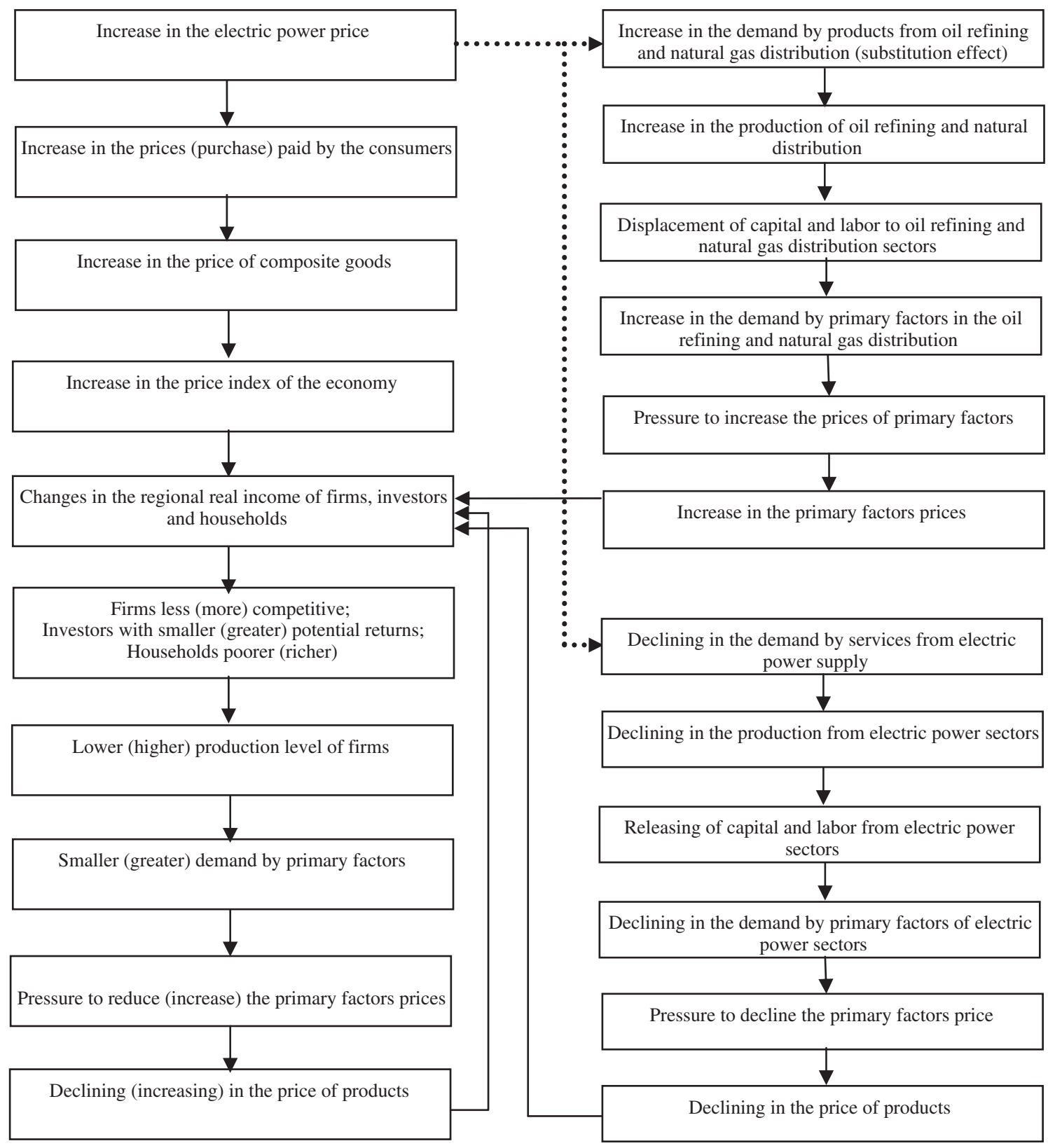

Fig. 6. Causal relationships underlining the system of equations of the ENERGYBR Model.

\subsection{Simulation strategy}

The objective of the simulations is to extract the regional impacts (winners and losers) of changes in the electric power tariff, trying to mimic the structural differences observed in the spatial evolution of tariffs among the Brazilian, states in the period from 1995 to 2008 , in a comparative-static framework (Fig. 7). Three different sets of shocks associated with tariff deviations are considered in the simulations. Simulation 1 may be regarded as a control simulation in which a uniform 1\% increase in the price-shift term in Eq. (1) is introduced; Simulations 2 and 3 attempt to mimic the patterns of tariff deviations among the states that emerged in each of the two periods, before and after 2004.

Table 4 presents the size of the shocks that were introduced in the model. In Simulations 2 and 3, the first column presents the observed percentage variations in the electric power tariffs, while the second provides the normalization of this variation regarding the national average tariff. The magnitude of the shocks for Simulations 2 and 3 were estimated by taking the variation in the electric power tariff of each Brazilian state, for the two periods of reference presented in Fig. 7 (1995-2004 and 2004-2008), and normalizing it by the variation in the national electric power tariff. From these manipulations, an index was constructed for the variation in the tariff for each state regarding the national tariff for the two periods. This normalized index was introduced as a shock in the price-shift term in ICGE model, since the main objective is to capture the structure of the relative effects among regions.

In the Simulation 1, a uniform shock of $1.0 \%$ is introduced in the electric power prices in all the 27 Brazilian states. The objective of this simulation is to evaluate the dissipation of exogenous shocks in the electric power prices on the Brazilian economic space in 2004. This year also marks the spatial convergence of electric power tariffs among the Brazilian states. Simulation 2 considers exogenous "reverse" shocks in state electric power prices. The objective is to assess the differential regional impacts of relative tariffs increases by states in the period 1995-2004. In this period, the tariff policy resulted in the tariffs 


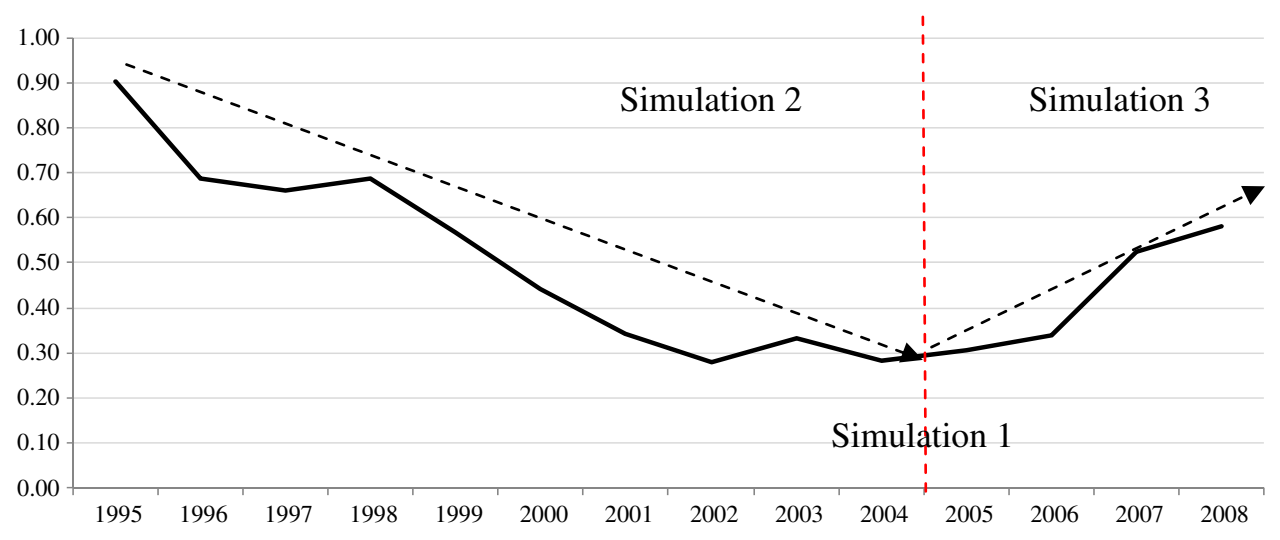

Fig. 7. Schematic representation of the simulations, considering the spatial evolution of standard deviation of electric power tariffs among the Brazilian states, 1995-2008.

converging, as described in Section 2. Regarding Simulation 3, exogenous shocks are also introduced in the electric power price-shift term to evaluate the regional impacts of the differentiated relative tariff increases among Brazilian states in the period 2004-2008. In this period, the tariff policy resulted in a significant transfer of productivity gains to final consumers in the regions characterized by the existence of a large economic concentration in Brazil, (see Section 2). For this reason, the purpose of this shock was to evaluate whether the new spatial pattern of electric power tariff variation (2004-2008) produces better or worse impacts, compared to results of the first period (19952004) regarding Simulation 2.

\section{Results}

In this section the macro, sectoral and regional results from the three simulations are presented and discussed.

\section{Table 4}

Description of the shocks in the electric power price. Source: ANEEL, 2009.

\begin{tabular}{|c|c|c|c|c|c|}
\hline \multirow[t]{2}{*}{ State } & \multirow{2}{*}{$\frac{\text { Simulation } 1}{\% \text { Shock }}$} & \multicolumn{2}{|l|}{ Simulation 2} & \multicolumn{2}{|l|}{ Simulation 3} \\
\hline & & $\begin{array}{l}\text { Price change } \\
(1995- \\
2004)\end{array}$ & $\begin{array}{l}\% \\
\text { Shock }\end{array}$ & $\begin{array}{l}\text { Price change } \\
(2004- \\
2008)\end{array}$ & $\begin{array}{l}\% \\
\text { Shocks }\end{array}$ \\
\hline Acre & 1.00 & 229.3 & 0.84 & 27.0 & 1.16 \\
\hline Amapá & 1.00 & 234.1 & 0.85 & 2.50 & 0.11 \\
\hline Amazonas & 1.00 & 186.6 & 0.68 & 49.0 & 2.11 \\
\hline Pará & 1.00 & 229.3 & 0.84 & 9.60 & 0.41 \\
\hline Rondônia & 1.00 & 139.9 & 0.51 & 30.9 & 1.33 \\
\hline Roraima & 1.00 & 162.6 & 0.59 & 39.8 & 1.72 \\
\hline Tocantins & 1.00 & 233.1 & 0.85 & 50.3 & 2.17 \\
\hline Alagoas & 1.00 & 208.6 & 0.76 & 53.9 & 2.32 \\
\hline Bahia & 1.00 & 263.5 & 0.96 & 23.1 & 1.00 \\
\hline Ceará & 1.00 & 232.9 & 0.85 & 25.6 & 1.11 \\
\hline Maranhão & 1.00 & 245.1 & 0.89 & 46.0 & 1.99 \\
\hline Paraíba & 1.00 & 233.0 & 0.85 & 39.0 & 1.68 \\
\hline Pernambuco & 1.00 & 219.7 & 0.80 & 44.3 & 1.91 \\
\hline Piauí & 1.00 & 218.5 & 0.80 & 59.3 & 2.56 \\
\hline Sergipe & 1.00 & 253.0 & 0.92 & 20.2 & 0.87 \\
\hline Rio Grande do Norte & 1.00 & 222.5 & 0.81 & 22.8 & 0.98 \\
\hline Distrito Federal & 1.00 & 252.0 & 0.92 & -2.70 & -0.12 \\
\hline Goiás & 1.00 & 244.1 & 0.89 & 14.4 & 0.62 \\
\hline Mato Grosso & 1.00 & 297.9 & 1.09 & 11.2 & 0.48 \\
\hline Mato Grosso do Sul & 1.00 & 287.0 & 1.05 & 31.1 & 1.34 \\
\hline Espírito Santo & 1.00 & 280.9 & 1.03 & 37.3 & 1.61 \\
\hline Minas Gerais & 1.00 & 330.1 & 1.21 & 55.4 & 2.39 \\
\hline Rio de Janeiro & 1.00 & 302.4 & 1.10 & 25.4 & 1.10 \\
\hline São Paulo & 1.00 & 285.0 & 1.04 & 12.5 & 0.54 \\
\hline Paraná & 1.00 & 209.7 & 0.77 & 18.1 & 0.78 \\
\hline Santa Catarina & 1.00 & 270.4 & 0.99 & 24.0 & 1.03 \\
\hline Rio Grande do Sul & 1.00 & 225.6 & 0.82 & 15.6 & 0.67 \\
\hline Brazil & 1.00 & 273.9 & 1.00 & 23.2 & 1.00 \\
\hline
\end{tabular}

\subsection{Macro results}

Table 5 presents the macro results from the three simulations. Considering the causal relationships depicted in Fig. 6, the uniform shock of $1.0 \%$ in the electric power prices causes an increase in all price indexes of macroeconomic variables. The GDP price index increases by $0.0272 \%$. The highest increases in the price indexes of the GDP components are found in consumer prices $(0.0318 \%)$ and in the regional government demand prices $(0.0392 \%)$. On the other hand, the lowest increases occur in the investment prices $(0.0014 \%)$ and in the import prices $(0.001 \%)$. As a consequence, the real income and the expectation of returns decrease, leading to a decline in economic activity. Factor income of capital and labor decreases because of the decline in the demand for these factors. On the other hand, in contrast to other primary factors, the factor land (which is fixed) presents an increase in its payment of $0.0448 \%$, even considering the decrease in the aggregate capital stock of $-0.0280 \%$. This is a consequence of the displacement of economic activity to the Agriculture and Livestock sector that experiences an increase in the rate of return because of the lower electric-power-intensity. The results regarding the aggregate demand show a decrease in all its components, mainly in the real investment expenditure $(-0.0265 \%)$ and in the real regional government demand $(-0.0392 \%)$ as a consequence of the reduction in factor income and, consequently, in the income-tax revenue. The overall macro results of the Simulation 1 is the decrease of $-0.0140 \%$ in the real GDP and a negative equivalent variation of $\mathrm{R} \$-494.41$ million.

In the Simulation 2, electric power tariffs increases in the Center-West and Center-South regions are higher than the national average. The GDP price index increases by $0.0195 \%$. The results for the GDP components show that the investment and imports' price indexes decrease by $-0.0068 \%$ and $-0.0010 \%$ respectively. For the other price indexes the impacts are positive, mainly on the consumer and regional government demand with respective increases of $0.0255 \%$ and $0.0352 \%$. Once again, the payments to land are the only ones that increase $(0.0168 \%)$. Among the components of aggregate demand, exports are the only component of final demand that presents a positive result $(0.0035 \%)$. The main aggregate result of this simulation is a decrease of $-0.0066 \%$ in the real GDP and a negative equivalent variation of $\mathrm{R} \$-230.94$ million. Comparing the results, the long-run negative impacts of Simulation 2 are considerably smaller than those from Simulation 1. The higher electric power price increases in the regions with lower electric power intensity and better possibilities of energy substitution might explain the better performance in this simulation.

Simulation 3 is designed to evaluate the impacts of the relative electric power price increases from 2004 to 2008, when the North and Northeast regions presented price increases higher than the national average; recall also that, in this period, the productivity gains from the electric power utilities companies started to be transferred 
Table 5

Long-run macro results (\% change).

Source: ENERGY-BR simulations.

\begin{tabular}{|c|c|c|c|}
\hline Variables & $\begin{array}{l}\text { Simulation } 1 \\
\text { (1.0\% Uniform) }\end{array}$ & $\begin{array}{l}\text { Simulation } 2 \\
(1995-2004)\end{array}$ & $\begin{array}{l}\text { Simulation } 3 \\
(2004-2008)\end{array}$ \\
\hline \multicolumn{4}{|l|}{ Prices } \\
\hline Investment price index & 0.0014 & -0.0068 & -0.0153 \\
\hline Consumer price index & 0.0318 & 0.0255 & 0.0124 \\
\hline Regional government demand price index & 0.0392 & 0.0352 & 0.0836 \\
\hline Federal government price index & 0.0089 & 0.0018 & 0.0178 \\
\hline Exports price index & 0.0087 & 0.0026 & -0.0165 \\
\hline Imports price index & 0.0018 & -0.0010 & -0.0328 \\
\hline GDP price index & 0.0272 & 0.0195 & 0.0201 \\
\hline \multicolumn{4}{|l|}{ Primary factors } \\
\hline Aggregate payments to capital & -0.0265 & -0.0277 & -0.0509 \\
\hline Aggregate payments to labor & -0.0287 & -0.0286 & -0.0379 \\
\hline Aggregate payments to land & 0.0448 & 0.0168 & 0.0338 \\
\hline Aggregate capital stock & -0.0280 & -0.0196 & -0.0395 \\
\hline \multicolumn{4}{|l|}{ Aggregate demand } \\
\hline Real household consumption & -0.0089 & -0.0018 & -0.0178 \\
\hline Aggregate real investment expenditure & -0.0265 & -0.0186 & -0.0350 \\
\hline Aggregate real regional government demand & -0.0392 & -0.0352 & -0.0835 \\
\hline Aggregate real federal government demand & -0.0089 & -0.0018 & -0.0178 \\
\hline Export volume & -0.0016 & 0.0035 & -0.0046 \\
\hline \multicolumn{4}{|l|}{ Aggregate indicators } \\
\hline Real GDP & -0.0140 & -0.0066 & -0.0257 \\
\hline Equivalent variation - total change in (US\$ million) & -494.41 & -230.94 & -801.60 \\
\hline
\end{tabular}

to consumers in the more developed regions. As can be seen in Table 5, GDP price index increases by $0.0201 \%$. Regarding its components, the investment, export and import price indexes present negative variation. However, the magnitudes of this negative variation are considerably smaller than the positive variation in the other indexes. The primary factor income presents variation in the same direction compared to the other two simulations, though the magnitudes are considerably higher. Payments to capital and labor decrease by $-0.0509 \%$ and $-0.0379 \%$, respectively, and payments to land increase by $0.0338 \%$. The decrease in the capital stocks is the lowest of the three simulations, -0.0395 . This simulation produces the strongest negative impact on the aggregate demand, considering that all its components decrease. The overall macro results are a decrease in real GDP by $-0.0257 \%$ and a negative equivalent variation of $\mathrm{R} \$$ -801.60 million. This simulation shows that even considering the transfer of productivity gains from electric power utility companies to final consumers, the tariff policy may not result in positive impacts on the real income and welfare levels. The higher electric power price increases in the regions with higher electric power intensity and weak possibilities of energy substitution are driving this result.

\subsection{Sectoral results}

The results from the three simulations concerning the sectoral activity level are presented in Fig. 8, according to the sectors described in Table 2. As can be seen, the impacts of the electric power price changes follow a general pattern where the electric power sectors (S16-S23) are the most negatively affected in the simulations. The decline in the electric power demand of the final consumers leads to the decline of the electric power intermediate demand of the electric power utilities companies, which in turn, results in the generalized decline in the electric power production from hydro and thermal sources. The Agriculture and Livestock sector (S1) presents an increase in the activity level in the three simulations. The smaller share of electric power in its production costs leads to a relative increase in the rate of return of this sector. This result may influence indirectly the performance of the Food and Beverage sector (S4).
Considering the assumptions regarding energy substitution implemented through the equations of the ENERGY-BR model, the electric power price changes result in an increase for the Natural Gas Utility Distribution (S24) sector. This is a trend in Brazil in the context of the diversification of the energy sources. In the last few years, the Brazilian government has stimulated the substitution among electric power and natural gas. Despite the increase in the activity level of Natural Gas Utility Distribution it must be highlighted that this result is not sufficient to prevent the activity level of the mining (oil and gas) sector (S2) from decreasing. This might be a consequence since the large amount of natural gas consumed in Brazil is not produced in the country, but imported from Bolivia.

Although the oil refining sector (S7) is an energy-intensive sector and could present a strongly negative performance, it must be pointed out that it competes with electric power. For this reason, the results for this sector are close to zero in Simulation 1, positive in Simulation 2 and only slightly negative in Simulation 3 when the electric power price increase is higher in the regions with weak possibilities of energy substitution. Although the activity level of electric power generation sectors strongly decreases, the thermoelectric generation sector demands only a slightly larger amount of intermediate products from the oil and refining sector. The thermoelectric generation with the intermediate use of natural gas is the main source of thermoelectric generation. Regarding the other energy-intensive sectors, the three simulations produce the expected results. The Cement sector ( $\mathrm{S} 10)$ presents one of the largest decreases in the sectoral activity in the simulations, followed by the Ceramic and Glass (S11) and Metallurgy of Steel and Iron (S12). The Metallurgy of Aluminum and Cooper (S13) sector, one of the most energy-intensive, does not experience strong declines in the activity level compared to the other sectors. As a matter of fact, around $50 \%$ of the electric power used by this sector in 2004 was directly supplied by the generation plants or from the self-production.

Comparing the sectoral results from the three simulations, it can be verified that in Simulation 2, the relatively higher increases in the electric power prices in the regions with better conditions of energy substitution lead to positive results for the natural gas utility distribution and oil refining. In the same way, non energy-intensive 
Simulation 1 (1,0\% uniform)

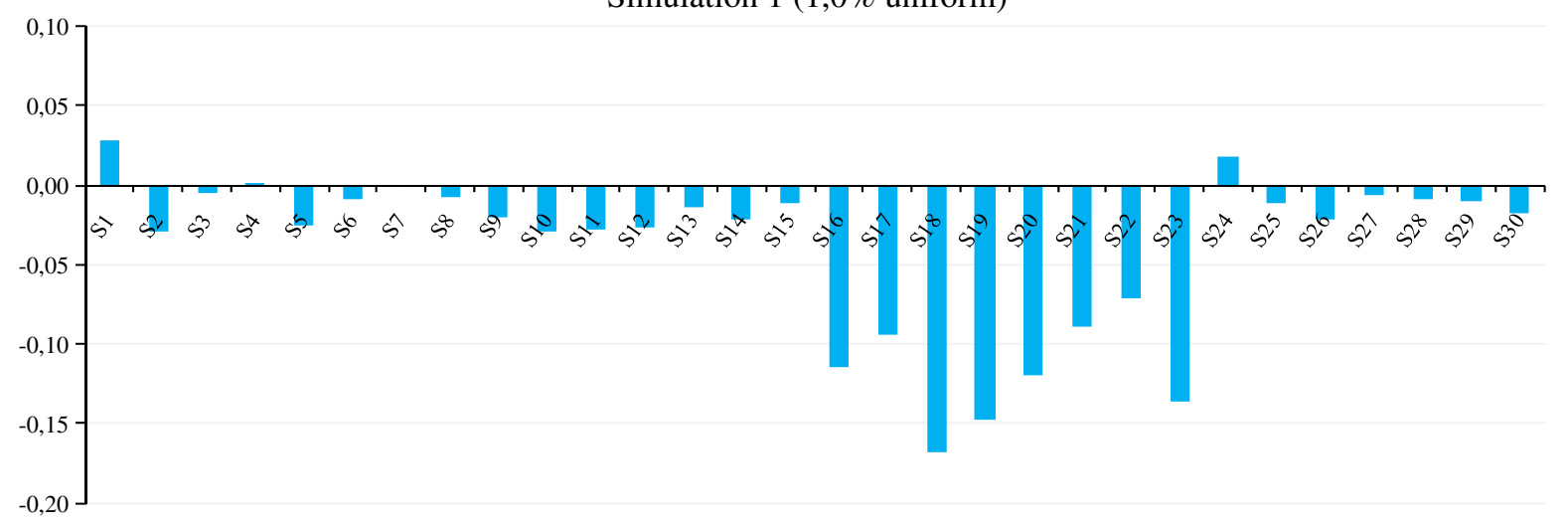

Simulation 2 (1995-2004)

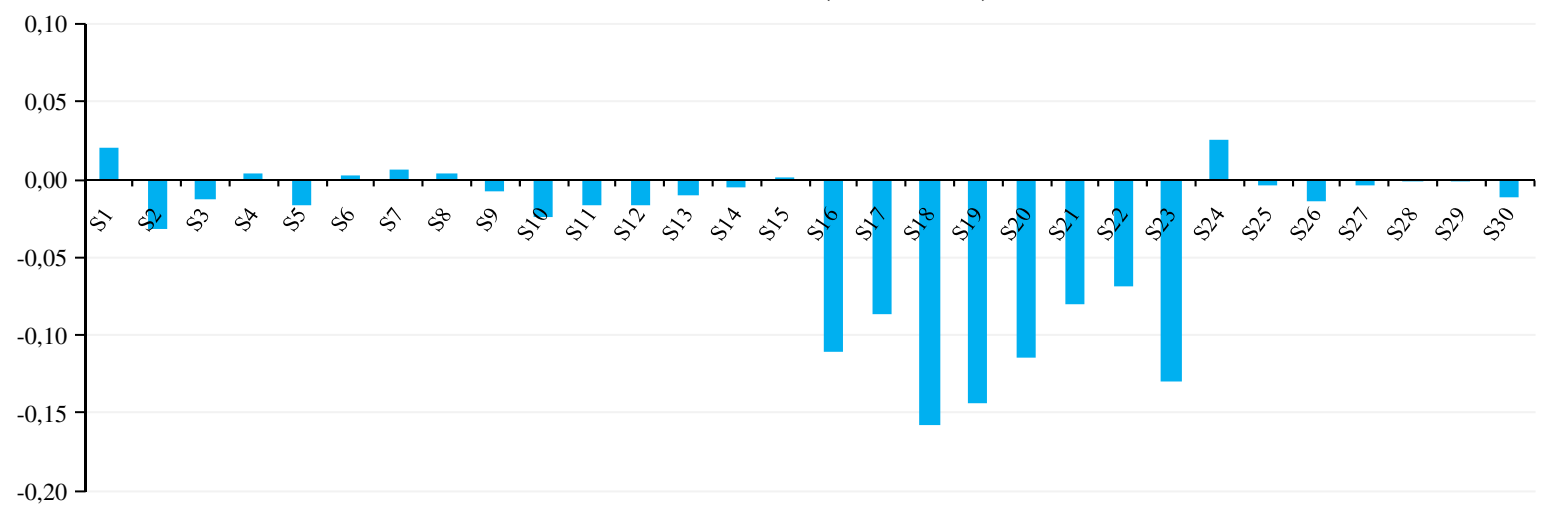

Simulation 3 (2004-2008)

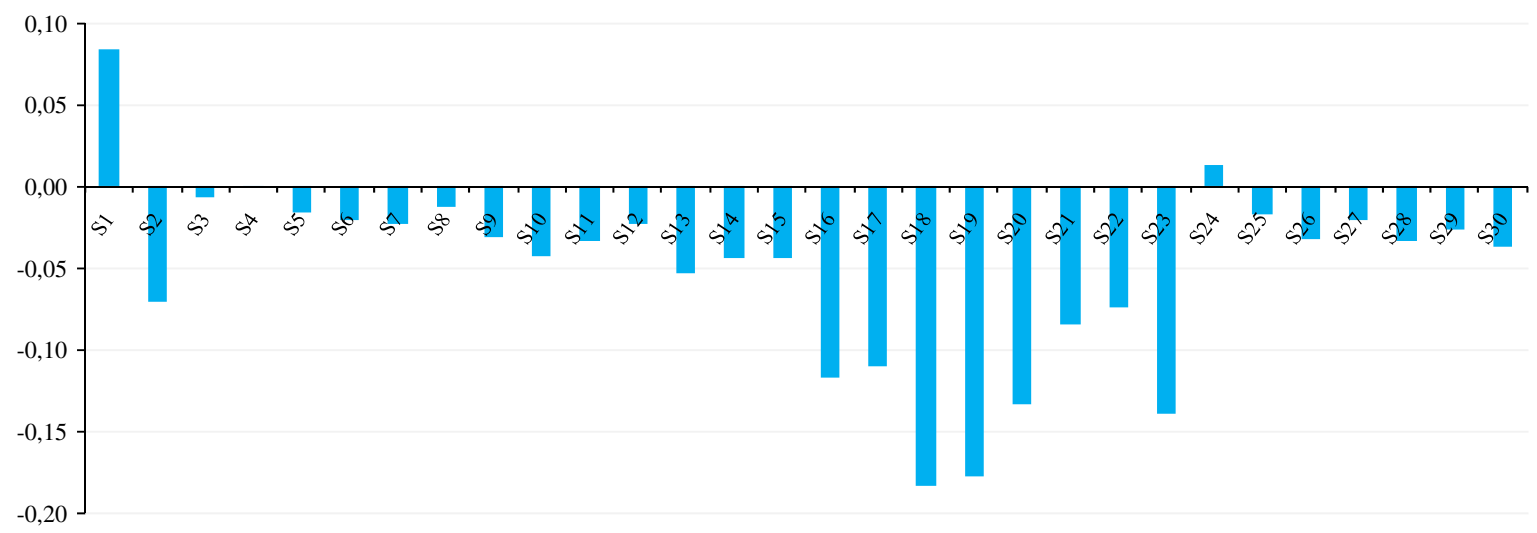

Fig. 8. Long-run sectoral results of electric power price changes, activity level (\% change).

sectors such as Agriculture and Livestock and Food and Beverage also present relatively good performances in the simulations, as a consequence of the endogenous adjustment of the rate of return.

\subsection{Regional results}

The regional results are presented in Fig. 9 where the light colors represent the negative impacts on the real GDP of the Brazilian states. In Simulation 1, the Northeast and Center-West regions are the most affected by the electric power price increases. However, the negative result of the Center-West region was strongly affected by the Distrito Federal, while in the Northeast region only the state of Sergipe does not experience a negative impact in the real GDP. In contrast, the North and South regions present positive responses in real GDP. Although the South and Southeast regions (Center-South) concentrate a large share of the energy-intensive activities, these regions present good performance in the simulations. Similarly, states with high shares of Agriculture and Livestock activity in the regional GDP (such as Tocantins, Paraná and Mato Grosso) also present a better performance.

In Simulation 2, although the electric power price increase is higher in the Center-West and Center-South, the Northeast region presents the largest decline in real GDP. The higher electric power-intensity in this region and the better possibilities of energy substitution in the Center-West and Center-South regions might provide the explanation for this result. In the North region, the considerable positive impact on real GDP of the state of Amazonas is due to the fact that this state presented one of the lowest electric power prices increases in the period.

Regarding Simulation 3, the negative impacts are distributed among several states within regions. The magnitude of these negative 

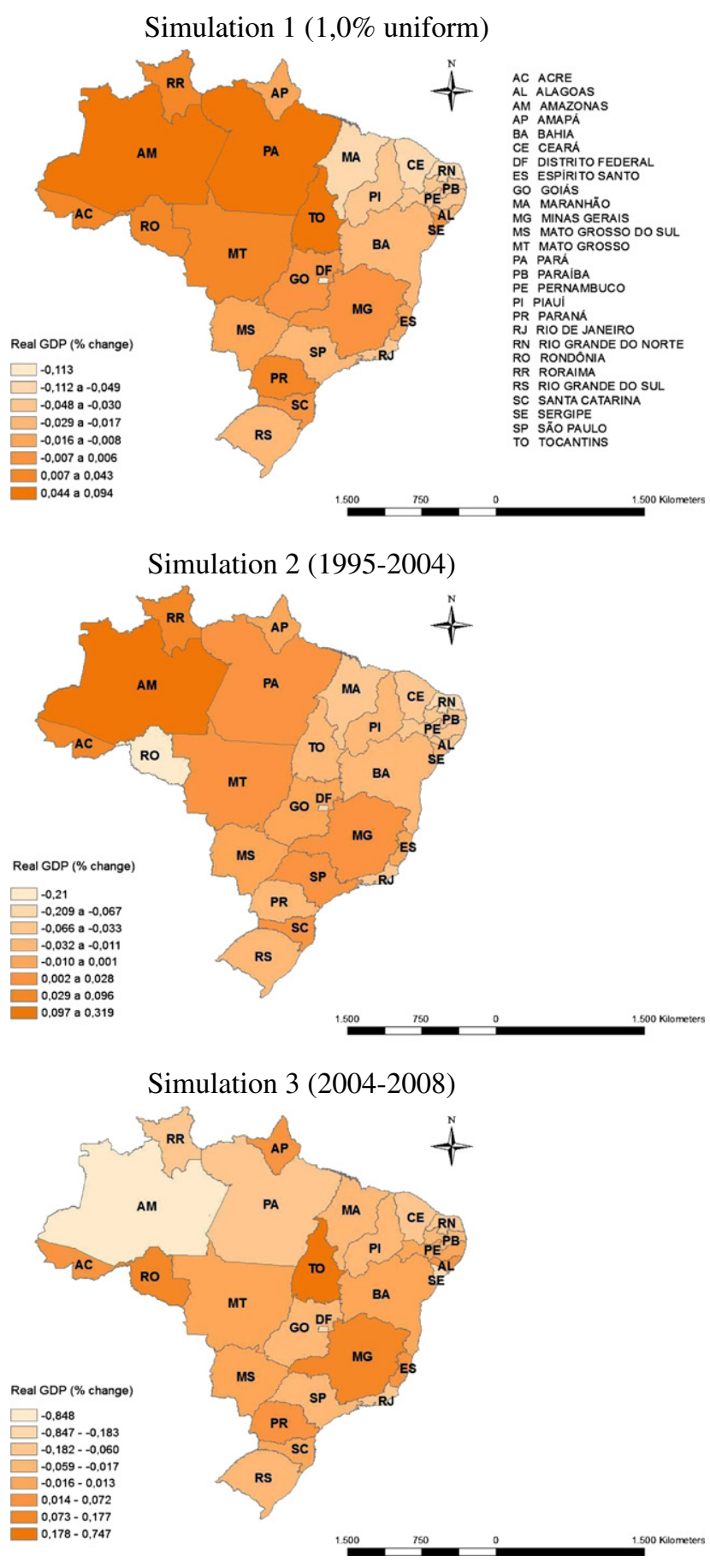

Fig. 9. Long-run regional impacts of electric power price changes, real GDP (\% change).

impacts is larger than those in Simulations 1 and 2. This might be a consequence of the higher price increases in the regions with higher electric power-intensity and also that these may be regions with limited possibilities for energy substitution. The South region is the unique region that presents a positive impact on real GDP. Furthermore, negative impacts in several states generate negative impacts on the state of São Paulo through interregional linkages.

In summary, the distribution of the regional impacts of the price increases regarding the three simulations derives from the heterogeneous distribution of the energy supply, jointly with the heterogeneous distribution of the economic activity in the Brazilian economic space. In Section 3, it was noted that the energy intensive sectors are the main channel through which the prices in electric power affect the equilibrium among regions. However, these sectors in Brazil are concentrated in regions with more possibilities of energy substitution in Brazil, such as Center-South regions. The negative impacts of the three simulations were more concentrated in the Northeast region, which is more electricity intensive due to weak possibilities of energy substitution. The positive impacts were towards states with low electric power intensity and strong agriculture activity, mainly due to displacement of investments guided by higher rates of return.

The results of Simulation 3 need to be highlighted, considering that it refers to the period of consolidation of the tariff policy and a new trend of electric power regional tariffs. The literature review in Section 3 highlighted the importance of non-tradable sectors, such as electric power and natural gas utilities, and their interrelationships for the decisions of location and for agglomeration economies. The same agglomeration economies determine increasing returns for these sectors, since industrialized regions provided the largest gains for consumers and suppliers of electric power. On the other hand, the agglomeration economies might influence the inequality of the energy supply, because they allow for long run investments in new sources such as natural gas utilities to be more fully exploited. As a consequence, and as revealed in Simulation 3, the recent trend of higher tariffs in the less developed regions is considerably harmful for the avowed goal of reducing regional disparities in the Brazilian economy.

\subsection{Systematic sensitivity analysis}

In the calibration and in the simulation process with the ENERGY-BR model, at least three sets of key parameters were used: regional and international Armington trade elasticities; elasticity of substitution among energy sources; and elasticities of substitution among electric power sources. In order to increase confidence in the robustness of the results, systematic sensitivity analyses were carried out to evaluate the strength of these results concerning each one of the sets of key parameters. In this analysis, a $20 \%$ interval for variation in the parameters was adopted, with triangular distribution in the three levels of substitution. The reported confidence intervals of $90 \%$ were obtained from the results of median and standard deviation generated in the systematic sensitivity analysis, using the Chebychev inequality (limits of 3.16 standard deviation from the mean). Based on these intervals, it was possible to evaluate the sensitivity of the selected results to the parameters used.

The systematic sensitivity analysis showed that the results of the model are relatively robust. However it must be remarked that the Armington elasticities need to be reviewed. In addition, the conservative values for the parameter of energy and electric power sources substitution used in the simulations could have influenced the results; it will be important that in future studies about energy substitution in Brazil, more research effort is directed to parameter estimation. On the other hand, the sensitivity analysis also showed that the results of the models were more sensitive to international and regional trade elasticities than to energy substitution parameters. This finding could justify the importance of the use of ICGE for energy policy analysis in Brazil.

\section{Final remarks}

The objective of this paper was to evaluate the long-run regional impacts of tariff policy of the Brazilian electric power sector. From 1995 to 2008, there were two different trends of spatial distribution of electric power tariff among the Brazilian states, one of convergence and the other of spatial divergence. The former was guided by the elimination of tariff distortions, and the latter by the electric power tariff policy based on the price-cap method. In the search for theoretical elements to support energy studies in the regional science field, 
the relation between energy and location of economic activity was considered. The recent theoretical advances in the NEG, that allow the consideration of the vertical linkages and the factor mobility to explain agglomeration economies, seem well suited for the empirical problem presented. Furthermore, an ICGE model was designed and calibrated to evaluate energy policy issues in the Brazilian economy. Three simulations were carried using this model.

The results of Simulation 1 showed that the model provides good numerical representations of the theoretical causalities expressed in its system of equations. The macroeconomic results revealed that, in the long-run, a uniform increase of $1.0 \%$ in the electric power prices in Brazil had negative impacts on income and welfare. At the sectoral level, energy and energy-intensive sectors were the most affected. The natural gas and oil refining sectors that compete with electric power benefitted most in the simulations. On the other hand, the low electric-power-intensity and the capital mobility determined the relocation of production to agriculture and food sectors. The regional results showed that the most affected regions were the poorest, with the highest electric-power-intensity and the weakest possibilities of energy substitution. Despite the high concentration of energy intensive sectors in the Center-South, the low electricpower-intensity and the best possibilities of energy substitution in this region resulted in positive relative returns that attracted capital and improved the real GDP in same states. The contrary effects occurred in the Northeast region.

Simulation 2 showed that the patterns of spatial evolution of tariff increases from 1995 to 2004 may have resulted in negative macroeconomic impacts that were less intensive than those from Simulation 1. Although the Center-West and Center-South regions experienced the highest electric power tariff increases during the process of the tariff convergence, the most negative results were not concentrated in these two regions. In some states of these regions, the results were indirectly positive; low electric-power-intensity and better conditions for energy substitution might explain this result. At the sectoral level, the higher activity level in the oil refining and natural gas utility distribution reinforced the importance of energy substitution process for the results. On the other hand, the Northeast regions continued to present negative effects.

Finally, Simulation 3 showed that the pattern of spatial evolution of tariff increasing from 2004 to 2008 resulted in the strongest negative macroeconomic impacts on the Brazilian economy. The tariff policy that distributes productivity gains to final consumers did not produce positive results for the economy as a whole. The highest tariff increases in the North and Northeast regions in the period determined that these two regions were the most affected. The higher electric-power-intensity and minor possibilities of energy substitution in these regions that generated negative impacts were transmitted to the other regions through the trade flows. In addition, the strongest decline in the real GDP of the state of São Paulo must be highlighted. The dependence of the Brazilian regions regarding this state, and vice versa, seems to be an important determinant of the regional impacts. For this reason, the qualitative and quantitative analyses were strongly sensitive to regional trade elasticities.

An important result of the research was that higher electric power tariff increases in the regions with higher electric-power-intensity and minor possibilities of energy substitution generate the most negative impacts on the economy. The negative impacts might overcome the positive impacts of the transference of productivity gains to final consumers in the most developed regions. For this reason, the recent trend of spatial evolution of electric power tariffs might generate strong negative impacts on the economy and contribute to increases in regional inequalities. Regarding the results of the sensitivity analysis, besides the revision in some Armington elasticities, the introduction of the oil refining sector in the energy substitution structure needs to be revaluated. On the other hand, the results of the model were more sensitive to Armington elasticities than to energy substitution elasticities. This finding justifies the importance of the ICGE models to incorporate spatial elements for the energy policy analysis in Brazil.

The energy supply is considerably capital-intensive. For some energy sources, such as natural gas for example, the diversification depends on large-scale demand for the investments to become economically feasible. For this reason, the energy diversification is unbalanced in Brazil. This might deepen some regional inequality problems. The relationship between energy and location of economic activity must be considered in the regional development policies. The federal and state governments might create mechanisms to stimulate investments in new energy sources in the regions where only the market forces are not sufficient to ensure the return on investments.

Future extensions of this research should be focused on the structure of energy substitution in Brazil and estimation of the respective key parameters of energy substitution. In addition, because of the electric power tariffs differentials among the Brazilian regions, the evaluation of the impacts of the taxes differentials among the states needs to be evaluated. This subject has been discussed in Brazil because of the state policy of considering tax increases on goods with inelastic demand, such as electric power.

\section{References}

Adams, P., et al., 2003. MMRF-GREEN: a dynamic multi-regional applied general equilibrium model of the Australian economy, based on the MMR and Monash models Working Paper. Centre of Policy Studies/IMPACT Centre, Monash University. g-140. Available at: $<$ www.monash.edu.au/policy $>$.

Agência Nacional de Energia Elétrica - ANEEL, 2009. Consumo setorial de energia elétrica . Brasília, DF.

Anselin, L., 1988. Spatial Econometrics: methods and models. Kluwer Academic Publishers, Dordrecht.

Azzoni, C.R., 2001. Economic growth and regional income inequality in Brazil. Ann. Reg. Sci. 35 (1), 133-152.

Dixon, P., Rimmer, M., 2002. Dynamic General Equilibrium Modeling for Forecasting and Policy: a Practical Guide and Documentation of MONASH. North-Holland, Amsterdam.

Dixon, P., et al., 1982. ORANI, A Multi-sectoral Model of the Australian Economy. NorthHolland, Amsterdam.

Dixon, Peter, et al., 1992. Notes and Problem in Applied General Equilibrium Economics. North-Holland, Amsterdam.

Fujita, M., et al., 1999. The Spatial Economy: Cities, Regions, and International Trade. MIT Press, USA.

Guilhoto, J.J.M., 2008. Matriz interestadual de insumo-produto 2004. Universidade de São Paulo, Instituto de Pesquisas Econômicas, São Paulo, SP.

Haddad, E.A., 1999. Regional Inequality and Structural Changes: Lessons from the Brazilian Economy. Ashgate, Aldershot.

Haddad, E.A., 2004. Retornos crescentes, custos de transporte e crescimento regional Tese (Livre Docência), Faculdade de Economia Administração e Contabilidade da Universidade de São Paulo, São Paulo, SP.

Haddad, E.A., Hewings, G.J.D., 2005. Market imperfections in a spatial economy: some experimental results. Q. Rev. Econ. Finance 45, 476-496.

Haddad, E.A., et al., 2008. Avaliação dos impactos econômicos das políticas de infraestrutura de transportes no Brasil: uma aplicação a duas rodovias federais em Minas Gerais. Cadernos BDMG. 16, 29-72.

Hanoch, G., 1971. CRESH production functions. Econometrica 39 (5), 695-712.

Hinchy, M., Hanslow, K., 1996. The MEGABARE Model: Interim Documentation. Australian Bureau of Agricultural and Resource Economics. Available at: <http:// www.abareconomics.com $>$.

Horridge, J.M., et al., 2008. Release 10.0 of GEMPACK: New Features and Changes from 9.0. GEMPACK User Documentation GPD-9. IMPACT Project and KPSOFT Monash University, Australia.

Krugman, P., 1980. Scale economies, product differentiation, and the pattern of trade. Am. Econ. Rev. 70 (5), 950-959.

Krugman, P., 1991. Increasing returns and economic geography. J. Polit. Econ. 99 (3), 483-499.

Lakshmanan, T., 1981. Regional growth and energy determinants: implications for the future. Energy J. 2 (2), 1-24.

Lakshmanan, T. Bolton, R., 1986. Regional energy and environmental analysis. In: Nijkamp, P. (Org). Handbook of Regional and Urban Economics, v 01. North Holland, p. 581-628.

Landi, Mônica. Energia elétrica e políticas públicas: a experiência do setor elétrico brasileiro no período 1934 a 2005. São Paulo, 2006. Tese (Doutorado em Energia) - Programa Interunidades em Energia, Instituto de Energia e Eletrotécnica, Universidade de São Paulo.

Littlechild, S., 1983. Regulation of British Telecom's profitability. Department of Industry, London.

Miernyk, W., 1976. Some regional impacts of the rising costs of energy. Pap. Reg. Sci. Assoc. 37 (1), 213-227. 
Miernyk, W., 1977. Rising energy prices and regional economic development. Growth Change 8 (3), 2-7.

Nijkamp, P., 1980. Energy problems and regional development: editorial note. Reg. Sci. Urban Econ. 10 (3), 299-301.

Nijkamp, P., 1983. Regional dimensions of energy scarcity. Environ. Plan. C 1 (2), 179-192.

Nijkamp, P., Parrels, A., 1988. Impacts of electricity rates on industrial location. Energy Econ. 10 (2), 107-116.

Ramos-Real, F.J., et al., 2009. The evolution and main determinants of productivity in Brazilian electricity distribution 1998-2005: an empirical analysis. Energy Econ. 31 (2), 298-305.

Sales, J.C.F., 2009. Avaliação do processo de revisão tarifária periódica das concessionárias de distribuição de energia elétrica no Brasil. Campinas. Dissertação (Mestrado). Programa de Pós-Graduação da Faculdade de Engenharia Mecânica, Planejamento de Sistemas Energéticos, Universidade de Campinas.
Santos, G.F., 2010. Política energética e desigualdades regionais na economia brasileira. São Paulo. Tese (Doutorado em Economia) - Programa de Pós-Graduação em Economia, Faculdade de Economia Administração e Contabilidade da Universidade de São Paulo. Santos, G.F., et al., 2009. Spatial interactions between energy and energy-intensive sectors in the Brazilian economy: a field of influence approach. 17 Conferência Internacional Input-Output, University of São Paulo, Brasil.

Tovar, B., et al., 2009. Productivity Evolution and Scale Effects in Brazilian Electricity Distribution Industry: Evidence From 1998-2005 Period. Fundación de Estudios de Economía Aplicada. Available at: <http://www.fedea.es>. 